\title{
The Relationships between Coaches' Leadership Styles, Competitive State Anxiety, and Golf Performance in Korean Junior Golfers
}

\author{
Chul-Ho BUM ${ }^{1}$ Stephen H. SHIN ${ }^{2}$
}

\begin{abstract}
he purpose of this study was to determine whether Korean junior golf coaches' leadership styles affect athletes' competitive state anxiety before a game as well as their performance. In the Multidimensional Model of Leadership (MML), Chelladurai and Saleh (1980) identified five aspects of leadership behavior in coaching: training/instruction, democratic behavior, autocratic behavior, social support, and positive feedback. A survey was conducted with junior golfers participating in the $23^{\text {rd }}$ Korean National Middle and High School Championship. Data from 216 questionnaires were used in the analysis. Multiple regression analyses were run on the data, revealing the following results. First, training/instruction and social support of coaches decreased cognitive anxiety before the game, whereas autocratic behavior increased it. Second, training/instruction and positive feedback of coaches increased self-confidence before the game. Third, training/ instruction of coaches increased golf performance, whereas autocratic behavior decreased it. Finally, cognitive anxiety of golf athletes was found to reduce golf performance, whereas self-confidence increased it. Consequently, this study may deliver sport administrators and parents with understanding of how coaches' leadership styles could influence on junior golfers' psychological state and golf performance.
\end{abstract}

Keywords: leadership styles, competitive state anxiety, golf, performance

\footnotetext{
Kyung Hee University, Gyeonggi-do, South Korea
}

${ }^{2}$ Belmont University, Nashville, Tennessee, USA 


\section{Introduction}

The role of coaches in mentoring athletes and ensuring their mental health has become increasingly important in competitive sports. Golf coaches play a particularly important role in this regard compared to coaches in other sports, because golfer's psychological state has a major impact on his/her performance (Finn, 2008; Hellstrom, 2009). This may be partly due to the relatively short time golfers have for playing and the long time they spend waiting their turn or moving across the course (Bois, Sarrazin, Southon, \& Boiche, 2009). Kim and Han (2004) argued that the most common reason a player misses shots is his/ her mindset. They also noted that anxiety is a major factor in disrupting mental balance. Therefore, the role of the coach in golf is not confined to technical assistance; it also involves psychological support.

The number of golfers in South Korea has been increasing steadily. According to Kim (2002), the rise is due to an increase in leisure time and in interest in health, both owing to economic growth. There were 1,311 junior golfers registered with the Korea Junior Golf Association (KJGA) in 2000, which rose to 2,030 in 2013 (KJGA, 2013). However, currently few golf coaches actually have a formal coaching education, due to the preference of Koreans for coaches who have had a successful career as players over those who are well versed in coaching techniques. Therefore, this study may be helpful in fostering competent coaches in golf.

\section{Literature Review}

In the multidimensional model of leadership, Chelladurai and Saleh (1980) identified five aspects of leadership behavior in coaching. According to Chelladurai (1993), training/instruction prioritizes training and instructing the athletes to achieve better performance; democratic behavior involves sharing opinions with the athletes; autocratic behavior limits athletes' participation in decision-making process; social support focuses on forming mutual relations with the athletes; and, lastly, positive feedback involves complimenting athletes and encouraging them to achieve success in performance.

Drawing on multidimensional anxiety theory (MAT), Martens, Burton, Vealey, Bump, and Smith (1990) divided anxiety into three subcomponents: cognitive anxiety, somatic anxiety, and self-confidence. Cognitive anxiety is related to negative expectations or thoughts about performance, while somatic anxiety is how the nervous system becomes stimulated by anxiety-including situation, resulting in a physiological response (Martens, Vealey, \& Burton, 1990). Self-confidence is "one's belief in meeting the challenge of the task to 
be performed" (Woodman \& Hardy, 2003, p. 443). Some sports theorists have claimed that there is a significant relationship between cognitive anxiety and somatic anxiety (Caruso, Dzewaltoski, Gill, \& McElory, 1990; Jones, Cale, \& Kerwin, 1988; Krane, 1992; Morris, Davis, \& Hutchings, 1981). A relationship between somatic anxiety and sports performance lacks a theoretical foundation (Woodman \& Hardy, 2003). In reality, somatic anxiety varies over time, and thus is less likely to affect sports performance compared with cognitive anxiety (Martens, Vealey et al., 1990). Due to this debate over its relevance to sports, somatic anxiety was excluded from this study.

Previous studies have shown differing results in terms of what type of coaching behavior affects sports performance in a variety of sports. Training/ instruction was, for example, positively related to performance (Gordon, 1986; Rajabi, 2012). In contrast, democratic behavior has been found to be positively (Lee, 2007; Rajabi, 2012) and negatively related to sports achievement (Lan, 2009). Weiss and Friedrich (1986) found that social support was more likely to increase athletic performance.

In a study of Korean Taekwondo athletes, Hong (2008) found that training/instruction and positive feedback behavior reduced cognitive anxiety levels, and that training/instruction, social support, and democratic behavior were positively associated with self-confidence. A recent study showed that the training/instruction of junior taekwondo coaches significantly reduced cognitive anxiety and significantly increased self-confidence in junior taekwondo (Han, 2012). In a sample of college bowlers in Korea, both training/instruction and autocratic behavior significantly decreased bowling athletes' cognitive anxiety, whereas democratic behavior decreased self-confidence (Yeom, 2009). These contradictory findings may be due to the differing samples, settings, and sports used.

A negative relationship between cognitive anxiety and athletes' performance in sports has been found (Burton, 1988; Chamberlain \& Hale, 2007; Martens, Vealey et al., 1990), while a positive relationship has been shown between self-confidence and athletic performance (Chamberlain \& Hale, 2007; Doo, Kim, \& Lee, 2002; Martens, Vealey et al., 1990). However, it seems difficult to accurately demonstrate the possible relationships between coaches' leadership styles, athletes' competitive state anxiety, and sports performance. In an attempt to illuminate these issues, this study assessed the impact of different types of coaches' leadership styles in South Korea on junior golfers' competitive state anxiety levels before a game and their golf performance. The research questions in this study are as follows: 
- Do coaches' different leadership styles have an effect on junior golfers' competitive state anxiety levels before a tournament?

- Do coaches' different leadership styles have an effect on junior golfers' performance levels?

- Do junior golfers' different competitive state anxiety levels have an effect on their performance levels?

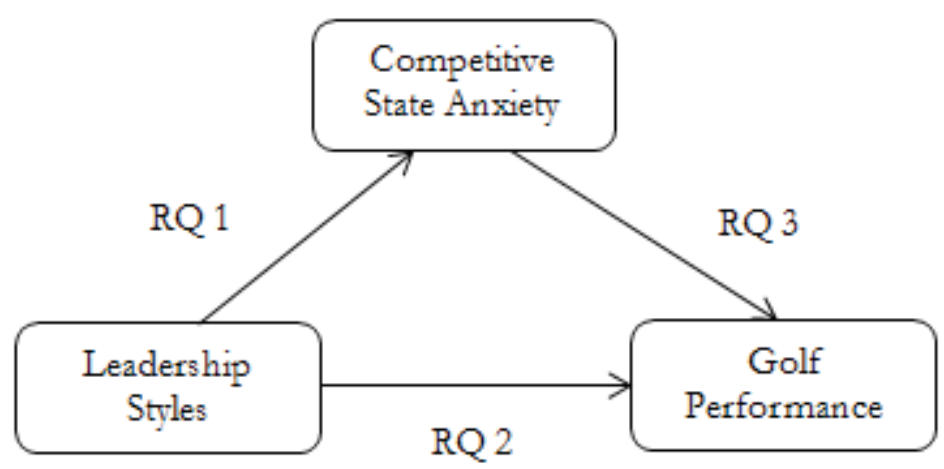

Figure 1. Relationships between Leadership Styles, Competitive State Anxiety, and Golf Performance

\section{Methods}

\section{Participants}

The participants were 232 student athletes between 12 and 18 years of age in the KJGA. Participants were recruited via convenience sampling at the $23^{\text {rd }}$ National Middle and High School Golf Championship, which was held on August 6-10, 2012, and data were obtained via a questionnaire. The tournament took place in the Gold Lake Country Club in South Korea. Of the questionnaires, 16 were excluded due to insincere responses. Consequently, the data of 216 questionnaires were used in the analysis in this study. The demographic characteristics of participants are shown in Table 1. 
Table 1

Demographic Characteristics of Participants

\begin{tabular}{cccc}
\hline & & Frequency & Percent $(\%)$ \\
\hline \multirow{2}{*}{ Gender } & Male & 127 & 58.8 \\
& Female & 89 & 41.2 \\
\hline \multirow{5}{*}{ School year } & Middle school 1 & 7 & 3.2 \\
& Middle school 2 & 33 & 15.3 \\
& Middle school 3 & 42 & 19.4 \\
& High school 1 & 31 & 14.4 \\
& High school 2 & 66 & 30.6 \\
& High school 3 & 37 & 17.1 \\
\hline \multirow{5}{*}{ Golf experience } & $<2$ years & 69 & 31.9 \\
& 2 to $<4$ years & 77 & 35.6 \\
& 4 to $<6$ years & 48 & 22.2 \\
& $\geq 6$ years & 42 & 10.2 \\
\hline & & 216 & 100 \\
\hline
\end{tabular}

\section{Instruments}

The instruments used in this study were as follows: (a) the Leadership Scale for Sport (LSS), (b) the Competitive State Anxiety Inventory-2 (CSAI-2), and (c) each athlete's 18-hole round score in the preliminary round of the tournament. The LSS was developed by Chelladurai and Saleh (1980) and the CSAI-2 by Martens, Burton et al. (1990). The validity of the data of both the LSS and CSAI-2 was assessed using exploratory factor analysis with a varimax rotation. A reliability analysis was conducted using Cronbach's alpha. The results of validity and reliability of the LSS are shown in Table 2.

Table 2

Validity and Reliability of the LSS

\begin{tabular}{lcccccc}
\hline & Training & Democratic & Social & Autocratic & Positive & Cronbach's $\alpha$ \\
\hline Item 1 & .812 & & & & \\
Item 7 & .780 & & & \\
Item 2 & .759 & & & \\
Item 8 & .756 & & & \\
Item 13 & .748 & & & \\
Item 14 & .731 & & & \\
Item 19 & .716 & & & \\
\end{tabular}


Table 2 (continued)

\begin{tabular}{|c|c|c|c|c|c|c|}
\hline Item 26 & .708 & & & & & \\
\hline Item 25 & .693 & & & & & \\
\hline Item 20 & .662 & & & & & \\
\hline Item 35 & .661 & & & & & \\
\hline Item 3 & & .794 & & & & \\
\hline Item 9 & & .731 & & & & \\
\hline Item 27 & & .712 & & & & \\
\hline Item 31 & & .696 & & & & \\
\hline Item 21 & & .684 & & & & .866 \\
\hline Item 15 & & .680 & & & & \\
\hline Item 32 & & .673 & & & & \\
\hline Item 36 & & .660 & & & & \\
\hline Item 34 & & .634 & & & & \\
\hline Item 29 & & & .728 & & & \\
\hline Item 17 & & & .714 & & & \\
\hline Item 11 & & & .706 & & & \\
\hline Item 33 & & & .696 & & & .840 \\
\hline Item 23 & & & .673 & & & \\
\hline Item 5 & & & .671 & & & \\
\hline Item 37 & & & .646 & & & \\
\hline Item 38 & & & .642 & & & \\
\hline Item 4 & & & & .803 & & \\
\hline Item 10 & & & & .740 & & \\
\hline Item 16 & & & & .710 & & .741 \\
\hline Item 22 & & & & .653 & & \\
\hline Item 28 & & & & .615 & & \\
\hline Item 30 & & & & & .727 & \\
\hline Item 18 & & & & & .724 & \\
\hline Item 6 & & & & & .687 & .745 \\
\hline Item 12 & & & & & .664 & \\
\hline Item 24 & & & & & .637 & \\
\hline Eigenvalue & 6.084 & 4.529 & 3.875 & 2.650 & 2.626 & \\
\hline Variance $\%$ & 16.011 & 11.918 & 10.197 & 6.975 & 6.911 & \\
\hline
\end{tabular}

The CSAI-2 comprises 18 items in two dimensions and rated on a fourpoint Likert-type scale $(1=$ not at all, $2=$ somewhat, $3=$ moderately, and $4=$ always $)$. The results of the validity and reliability analyses of this instrument are in Table 3. 
Table 3

Validity and Reliability of the CSAI-2

\begin{tabular}{lccc}
\hline & Cognitive anxiety & Self-confidence & Cronbach's $\alpha$ \\
\hline Item 11 & .841 & & \\
Item 17 & .824 & & \\
Item 9 & .821 & & .927 \\
Item 13 & .819 & & \\
Item 15 & .801 & & \\
Item 7 & .793 & & \\
Item 5 & .767 & & \\
Item 3 & .755 & & .896 \\
Item 1 & .723 & .800 & \\
\hline Item 10 & & .781 & \\
Item 6 & & .758 & \\
Item 14 & & .749 & \\
Item 8 & & .736 & \\
Item 16 & & .727 & \\
Item 2 & & .717 & \\
Item 12 & & .693 & \\
Item 18 & & .671 & \\
Item 4 & & 4.936 & \\
\hline Eigenvalue & & 27.422 & \\
\hline Variance \% & & & \\
\hline
\end{tabular}

\section{Data Collection}

In order to gather data within the time available, a self-administered questionnaire was optimal. Approval by the Institutional Review Board for the protection of human subjects had been obtained prior to conducting the survey. For the purpose of confidentiality, the questionnaires were numbered (i.e., the athlete's name was not used). The data were collected during the $23^{\text {rd }}$ National Middle and High School Golf Championship over the first three days of the five-day event. During the preliminary rounds, each participating athlete's score was obtained from the official scoreboard after an 18-hole round.

\section{Statistical Analysis}

Statistical Package for the Social Sciences (SPSS) version 20.0 was used in this study. First, descriptive statistics were applied to the demographic characteristics of the survey participants. Second, the validity and reliability of 
the two measurement instruments were analyzed using exploratory factor analysis and Cronbach's alpha. Finally, multiple regression analysis was conducted to identify the possible relationships between the variables.

\section{Results}

\section{Correlation Analysis}

A correlation analysis was conducted using Pearson's coefficient (r) to investigate the relationship between the measured variables in this study. The results of the analysis are presented in Table 4.

Table 4

Correlations among the Measured Variables

\begin{tabular}{lcccccccc}
\hline \multicolumn{1}{c}{ Variable } & 1 & 2 & 3 & 4 & 5 & 6 & 7 & 8 \\
\hline Training/instruction & 1 & $.157^{*}$ & -.055 & -.081 & $.259^{* *}$ & $-.191^{* *}$ & $.345^{* *}$ & $-.380^{* *}$ \\
Democratic behavior & & 1 & .076 & .043 & .044 & .059 & .069 & .032 \\
Autocratic behavior & & & 1 & -.061 & -.023 & $.202^{* *}$ & -.105 & $.247^{* *}$ \\
Social support & & & 1 & -.030 & $-.321^{* *}$ & -.121 & -.003 \\
Positive feedback & & & & 1 & -.015 & $.350^{* *}$ & -.107 \\
Cognitive anxiety & & & & & & -.101 & $.480^{* *}$ \\
Confidence & & & & & & & & $-.338^{* *}$ \\
Golf performance & & & & & & & & 1 \\
\hline
\end{tabular}

\section{Research Question Testing}

Multiple regression analysis was conducted to determine the effect of coaches' leadership styles on junior golfers' competitive state anxiety levels before a tournament. First, leadership styles accounted for $19 \%$ of the variance in cognitive anxiety $\left(R^{2}=.189, F(5,210)=9.818, p<.001\right)$. Training/instruction $(\beta=-.233, p<.001)$, autocratic behavior $(\beta=.163, p<.01)$, and social support $(\beta=-$ $.333, p<.001)$ all had significant effects on athletes' cognitive anxiety levels, whereas democratic behavior and positive feedback did not have significant effects on it. Second, leadership styles accounted for $20.9 \%$ of the variance 
in self-confidence $\left(R^{2}=.209, F(5,210)=11.071, p<.001\right)$. Training/instruction $(\beta=.255, p<.001)$ and positive feedback $(\beta=.277, p<.001)$ had positive effects on self-confidence, whereas democratic behavior, autocratic behavior, and social support did not have significant effects on it. The results of the analysis are presented in Table 5.

Table 5

Multiple Regression Analyses for Competitive State Anxiety according to Leadership Styles

\begin{tabular}{|c|c|c|c|c|c|c|c|c|}
\hline Predictor & B & $S E$ & $\beta$ & $t$ & B & $S E$ & $\beta$ & $t$ \\
\hline मून & \multicolumn{4}{|c|}{ Cognitive Anxiety } & \multicolumn{4}{|c|}{ Self-Confidence } \\
\hline (Constant) & 3.475 & .457 & & 7.601 & 1.809 & .368 & & $4.912^{* * *}$ \\
\hline $\begin{array}{l}\text { Training/ } \\
\text { instruction }\end{array}$ & -.231 & .065 & -.233 & $-3.565 * * *$ & .206 & .052 & .255 & $3.948^{* * *}$ \\
\hline $\begin{array}{l}\text { Democratic } \\
\text { behavior }\end{array}$ & .122 & .080 & .096 & 1.522 & .029 & .065 & .028 & .455 \\
\hline $\begin{array}{l}\text { Autocratic } \\
\text { behavior }\end{array}$ & .175 & .067 & .163 & $2.599 * *$ & -.081 & .054 & -.093 & -1.503 \\
\hline $\begin{array}{l}\text { Social } \\
\text { support }\end{array}$ & & .071 & -.333 & $-5.317 * * *$ & -.092 & .058 & -.099 & -1.598 \\
\hline $\begin{array}{l}\text { Positive } \\
\text { feedback }\end{array}$ & .039 & .071 & .035 & .547 & .251 & .058 & .277 & $4.360^{* * *}$ \\
\hline
\end{tabular}

Multiple regression analysis was conducted to determine the effect of coaches' leadership styles on junior golfers' performance levels. Leadership styles accounted for $20.2 \%$ of the variance in golf performance $\left(R^{2}=.202\right.$, $F(5,210)=10.634, p<.001)$. Training/instruction $(\beta=-.380, p<.001)$ and autocratic behavior $(\beta=.219, p<.01)$ had significant effects on golf performance levels. The results of the analysis are presented in Table 6. 
Table 6

Multiple Regression Analysis for Golf Performance according to Leadership Styles

\begin{tabular}{lcccc}
\hline Predictor & $B$ & $S E$ & $\beta$ & $t$ \\
\hline (Constant) & 81.722 & 2.603 & & $31.397^{* * *}$ \\
Training/instruction & -2.163 & .370 & -.380 & $-5.854^{* * *}$ \\
Democratic behavior & .555 & .457 & .076 & 1.214 \\
Autocratic behavior & 1.348 & .382 & .219 & $3.527^{* *}$ \\
Social support & -.160 & .407 & -.024 & -.392 \\
Positive feedback & -.048 & .407 & -.008 & .118 \\
\hline \multicolumn{5}{r}{$\mathrm{R}^{2}=.202, F=10.634^{* * *}$} \\
\hline
\end{tabular}

Multiple regression analysis was conducted to determine whether junior golfers' competitive state anxiety levels influenced their performance levels. Cognitive anxiety and self-confidence accounted for $31.5 \%$ of the variance in golf performance $\left(R^{2}=.315, F(2,213)=43.938, p<.01\right)$. It was shown that both cognitive anxiety $(\beta=.450, p<.001)$ and self-confidence $(\beta=-.292, p<.001)$ had significant effects on performance. The results of the analysis are presented in Table 7.

Table 7

Multiple Regression Analysis for Golf Performance according to Competitive State Anxiety

\begin{tabular}{lcccc}
\hline Predictor & $B$ & $S E$ & $\beta$ & $t$ \\
\hline Constant) & 78.589 & 1.524 & & $51.557^{* * *}$ \\
Cognitive anxiety & 2.584 & .327 & .450 & $7.900^{* * *}$ \\
Self-confidence & -2.058 & .401 & -.292 & $-5.127^{* * *}$ \\
\hline \multicolumn{5}{c}{$R^{2}=.315, F=43.938^{* * *}$} \\
\hline
\end{tabular}




\section{Discussion}

This study examined the possible relationships between coaches' leadership styles, junior golfers' competitive state anxiety, and golf performance in South Korea. Training/instruction and social support decreased junior golfers' cognitive anxiety before the game, whereas autocratic behavior significantly increased anxiety. These results are consistent with previous studies in which coaches were found to influence athletes' psychological state (Chelladurai, 1993). Well-trained athletes whose coaches use training/instruction are more likely to approach competitions with emotional stability (Hong, 2008; Yeom, 2009). In golf, such emotional stability leads to a more regular swing tempo and rhythm, thereby reducing the number of missed shots (Kim \& Han, 2004). In other words, golfers with less training might experience cognitive anxiety before a game, which can lower their subsequent performance.

In addition, it can be assumed that a coach's efforts to continuously encourage, show sincere interest in, and maintain a close relationship with athletes is effective in reducing athletes' anxiety. Chelladurai and Saleh (1980) noted that autocratic behavior is characterized by one-way communication, where in coaches do not interact with the athlete. It may be inferred that the lack of interactive communication under autocratic leadership makes it difficult for these coaches to influence athletes' psychological well-being. Coaches' training/ instruction and positive feedback had significant positive effects on junior golfers' pre-competition self-confidence levels. These results are partially consistent with Hong's (2008) study that coaches' positive feedback further increases their selfconfidence levels especially when athletes show good performance.

Among the five leadership styles, only training/instruction had a positive effect on junior golfers' performance. This result matches those of Im (2008) and Rajabi (2012), who showed that training/instruction behavior improves sports performance. Taken together, it can be assumed that training under the guidance of a coach helps junior golfers acquire the skills needed for them to become proficient golfers. Second, a negative relationship was found between coaches' autocratic behavior and junior golfers' performance. The result of the present study supports the early findings of Gordon (1986) for Canadian intercollegiate football players, wherein coaches' authoritative leadership style decreased athletes' performance levels. Consequently, unlike in the past, a forceful leadership style is no longer considered an effective way of coaching junior golfers. Instead, this style leads to deterioration in their performance.

Junior golfers' cognitive anxiety before the game had a significant negative effect on their performance levels. This finding is consistent with past studies 
suggesting that there was a negative relationship between athletes' cognitive anxiety and their sports performance (Burton, 1998; Chamberlain \& Hale, 2007; Martens, Vealey et al., 1990). In golf, it can generally be assumed that an athlete's cognitive anxiety results in tense muscles that lead to losing swing tempo and rhythm. In effect, this can raise his/her chance of missing the shot, which hurts his/her performance. This study also found that the relationship between athletes' self-confidence and performance was significantly positive. This is consistent with the results of previous studies (Chamberlain \& Hale, 2007; Doo et al., 2002; Martens, Vealey et al., 1990). Chun and Kwak (2007) pointed out that self-confidence leads to thinking positively, reinforces concentration, and provides energy for achieving goals. Therefore, it can be inferred that these factors help junior golfers perform better.

Consequently, this study can be meaningful as it demonstrates a close connection between coaches' leadership styles, junior golfers' psychological state and golf performance. There has been a lack of Korean golf coaches who are well trained on mental and psychological coaching systematically. This study may help to cultivate more competent coaches who not only teach technical aspects of coaching, but also focus on the importance of psychological aspects of coaching. Also, coaches' effective and proper leadership styles are a significant factor for athlete's well-being and performance. Thus, this study may provide sport administrators and parents of Korean junior golfers with understanding of how coaches' leadership styles could influence their children to be successful on and off the golf courses.

\section{Limitations to Address for Future Study}

Due to the logistic difficulty of using a random sampling method for data collection, a non-probability sampling method was employed. Probability sampling methods should be used in follow-up studies to enhance the generalizability of the findings. This study looked only at Korean junior golf athletes. For the purpose of cross-cultural comparison using similar samples, it is suggested to replicate this method to compare results between the United States and Korea. Further follow-up studies could expand the target population to intercollegiate golf athletes, professional golfers, or other sports athletes. 


\section{References}

Burton, D. (1988). Do anxious swimmers swim slower? Re-examining the elusive anxiety-performance relationship. Journal of Sport and Exercise Psychology, 10, 45-61.

Bois, J. E., Sarrazin, P. G., Southon, J., \& Boiche, J. C. S. (2009). Psychological characteristics and their relation to performance professional golfers. The Sport Psychologist, 23, 252-270.

Caruso, C. M., Dzewaltoski, D. A., Gill, D. L., \& McElroy, M. (1990). Psychological changes in competitive state anxiety during noncompetition and competitive success and failure. Journal of Sport and Exercise Psychology, 12(1), 6-20.

Chamberlain, S. T., \& Hale, B. D. (2007). Competitive state anxiety and selfconfidence: Intensity and direction as relative predictors of performance on a golf putting task. Anxiety, Stress \& Coping, 20(2), 197-207.

Chelladurai, P. (1993). Leadership. In R. N. Singer, M. Murphy, \& L. K. Tennant (Eds.), Handbook on Research on Sport Psychology (pp. 647-671). New York: McMillan.

Chelladurai, O., \& Saleh, S. D. (1980). Dimension of leader behavior in sports: Development of a leadership scale. Journal of Sport Psychology, 2, 34-45.

Chun, M. H., \& Kwak, E. J. (2007). Sports Psychology for the Sports Leaders. Mapo-gu, Seoul: Bo-Kyung Cultural History.

Doo. M. K., Kim, Y. S., \& Lee, H. S. (2002). The effects of competitive state anxiety on performance of badminton players. Research on Physical Fitness, 25(1), 37-45.

Finn, J. (2008). An introduction to using mental skills to enhance performance in golf: Beyond the bounds of positive and negative thinking. International Journal of Sports Science \& Coaching, 3(0), 255-269.

Gordon, A. M. D. (1986). Behavioral correlates of coaching effectiveness (Unpublished doctoral dissertation). University of Alberta, Canada.

Han, J. M. (2012). The effects of leadership behavior patterns on the competitive anxiety of taekwondo athletes (Master's thesis). Sogang University, South Korea. 
Hellstrom, J. (2009). Psychological hallmarks of skilled golfers. Sports Medicine, 39(10), 845-855.

Hong, U. P. (2008). An effect of a coaching behavior of Taekwondo master on the competitive states anxiety of players (Master's thesis). Yong-In University, South Korea.

Im, B. H. (2008). Possible effects of Hockey coaches' leadership style on players' satisfaction and performance. (Master's thesis). Kook-Min University, South Korea.

Jones, J. G., Cale, A., \& Kerwin, D. G. (1988). Multidimensional competitive state anxiety and psychomotor performance. Australian Journal of Science and Medicine, 20, 3-7.

Kim, K. H., \& Han, K. H. (2004). Golf. Sillim-dong, Gwanak-gu, Seoul, South Korea

Kim, H. B. (2002). A study on current situation and development of the golf industry in Korea. Industrial Science Research Collection of Dissertations, 7(1), 115126.

Korea Junior Golf Association (2013). Membership. Retrieved from http://www. kjga.or.kr/n_Public/s45.asp

Krane, V. (1992). Conceptual and methodological considerations in sport anxiety research: From the Inverted-U hypothesis to catastrophe theory. Quest, 44(1), $72-87$.

Lan, W. J. (2009). The relationship between athlete's perception of intercollegiate basketball coach leadership behavior and team cohesiveness in Taiwan (Doctoral dissertation), Taiwan.

Lee, S. Y. (2007). The effect of leadership style of golf coach's on satisfaction of athletes and performance (Doctoral dissertation). Kyonggi University, South Korea.

Martens, R., Burton, D., Vealey, R., Bump, L., \& Smith, D. (1990). The development of the Competitive State Anxiety Inverntory-2 (CSAI-2). In R. Martens, R. S. Vealey, \& D. Burton (Eds.), Competitive anxiety in sport (pp. 117-190). Champaign, IL: Human Kinetics.

Martens, R., Vealey, R. S., \& Burton, D. (1990). Competitive anxiety in sport. Champaign, IL: Human Kinetics. 
Morris, L. W., Davis, M. A., \& Hutchings, C. H. (1981). Cognitive and emotional components of anxiety: Literature review and revised worry-emotionality scale. Journal of Educational Psychology, 73(4), 541-555.

Rajabi,Z. (2012). Relationship of coach's leadership style and player performance outcomes. European Journal of Experimental Biology, 2(4), 1134-1136.

Yeom, S. S. (2009). Effect of coaching style on the bowling trainee's competitive state anxiety. (Master's thesis). Konkuk University, South Korea.

Weiss, M. R., \& Friedrichs, W. D. (1986). The influence of leader behaviors, coach attributes, and institutional variables on performance and satisfaction of collegiate basketball teams. Journal of Sport Psychology, 8, 332-346.

Woodman, T., \& Hardy, L. (2003). The relative impact of cognitive anxiety and self-confidence upon sport performance: a meta-analysis. Journal of Sports Sciences, 21, 443-457.

Chul-Ho BUM, PhD is a lecturer in the Department of Golf Industry at Kyung Hee University in South Korea. Bum's research interests lie in the areas of coaching pedagogy, athletes' psychological well-being as well as sports performance.

Stephen Hankil SHIN, PhD is an Assistant Professor in the Department of Sport Science at Belmont University in the United States. He is a member of the North American Society for Sport Management (NASSM). Shin's research interests lie in the areas of organizational behavior/leadership, coaching pedagogy/psychology as well as ethnic consumer behavior in the acculturation process.

\section{Corresponding address:}

Dr. Stephen H. Shin

Department of Sport Science

Belmont University

1900 Belmont Blvd.

Nashville, Tennessee 37212, USA

Email: stephen.shin@belmont.edu 
